16:703-711.

35. Beck WC. The surgical mask: another 'sacred cow'? AORN J 1992:55:955-957.

36. Beck WC. The surgical mask. The Guthrie Journal 1993;62:97-98.

37. Meleny FL, Stevens FA. Postoperative haemolytic Streptococcus wound infections and their relation to haemolytic Streptococcus carriers among the operating personnel. Surg Gynecol Obstet
1926:43:338-342.

38. Meleny FL. Infection in clean operative wounds: a nine-year study. Surg Gynecol Obstet 1935;60:264-275.

39. Koch F. Perspectives in surgical attire. Infect Control Steril Tech 1996;2:15-17.

\title{
Perinatal AIDS Declines
}

\section{by Gina Pugliese, RN, MS Martin S. Favero, PhD}

As of September 30, 1996, a total of 566,002 AIDS cases among children were reported in the United States, including 7,472 cases among children aged $<13$ years. The majority of these cases acquired their HIV infection perinatally from their mothers. From 1992 to 1995, the estimated annual number of perinatally acquired AIDS cases declined 27\% from 905 to 663. The CDC has commented that this decline in perinatal transmission probably reflects the effect of perinatal zidovudine therapy and that increasing proportions of women may be accepting voluntary prenatal HIV testing and using zidovudine (ZDV) to prevent perinatal transmission. In 1994, results of clinical trials demonstrating effective therapy for reducing perinatal HIV transmission indicated a two-thirds decrease in such transmission associated with ZDV for HIV-infected pregnant women and their newborns. The Public Health Service issued recommendations in 1994 for ZDV treatment to reduce perinatal HIV transmission, and in 1985 for routine HIV counseling and testing for all pregnant women in the United States. Unfortunately, the $\mathrm{ZDV}$ regimen is not an affordable prevention strategy in many coun- tries where HIV prevalence rates are highest. Worldwide, an estimated 8.8 million women and 800,000 children have HIV infection; most of these persons reside in sub-Sahara Africa where resources are limited. Because ZDV treatment is not universally effective in preventing transmission nor is it always available, primary prevention of HIV infection among children will continue to require preventing new HIV infection among women in all countries.

FROM: Centers for Disease Control and Prevention. AIDS among children-United States, 1996. MMWR 1996;45:1005-1010. 